\title{
8. Classifiers
}

1. Introduction

2. Classifiers and classifier categories

3. Classifier verbs

4. Classifiers in signs other than classifier verbs

5. The acquisition of classifiers in sign languages

6. Classifiers in spoken and sign languages: a comparison

7. Conclusion

8. Literature

\section{Abstract}

Classifiers (currently also called 'depicting handshapes'), are observed in almost all sign languages studied to date and form a well-researched topic in sign language linguistics. Yet, these elements are still subject to much debate with respect to a variety of matters. Several different categories of classifiers have been posited on the basis of their semantics and the linguistic context in which they occur. The function(s) of classifiers are not fully clear yet. Similarly, there are differing opinions regarding their structure and the structure of the signs in which they appear. Partly as a result of comparison to classifiers in spoken languages, the term 'classifier' itself is under debate. In contrast to these disagreements, most studies on the acquisition of classifier constructions seem to consent that these are difficult to master for Deaf children. This article presents and discusses all these issues from the viewpoint that classifiers are linguistic elements.

\section{Introduction}

This chapter is about classifiers in sign languages and the structures in which they occur. Classifiers are reported to occur in almost all sign languages researched to date (a notable exception is Adamorobe Sign Language (AdaSL) as reported by Nyst (2007)). Classifiers are generally considered to be morphemes with a non-specific meaning, which are expressed by particular configurations of the manual articulator (or: hands) and which represent entities by denoting salient characteristics. Some examples of classifier constructions from different sign languages are shown in (1): Jordanian Sign Language (LiU; Hendriks 2008, 142); Turkish Sign Language (TID); HongKong Sign Language (HKSL; Tang 2003, 153); Sign Language of the Netherlands (NGT); Kata Kolok (KK); German Sign Language (DGS); American Sign Language (ASL; Brentari 1999, 21); and French Sign Language (LSF; Cuxac/Sallandre 2007, 18).

Although little cross-linguistic work has been undertaken so far, the descriptions and examples of classifiers in various sign languages appear quite similar (except for the classifier inventories, although there, too, many similarities exist). Therefore, in this chapter, the phenomenon of classifiers will be described as comparable in all sign 
(1)

a.

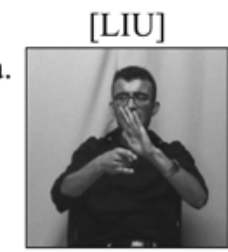

LH: CL:wide entity

RH: CL:vehicle

'car under bridge'

[KK]

e.

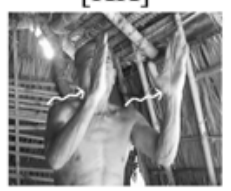

LH: CL:animal

RH: CL:animal

'two water

buffaloes move

forward'

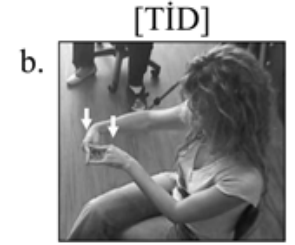

CL:square entity

CL:square entity $\}$

'notebook lying

here'

[DGS]

f.

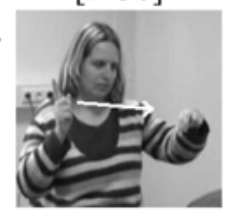

CL:legged entity

CL:animate entity

'man moves

towards woman'

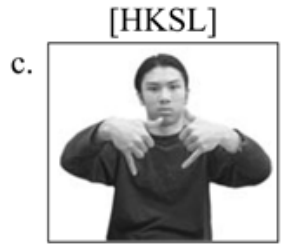

CL:animate entity

CL:animate entity

'two persons

standing opposite each other'

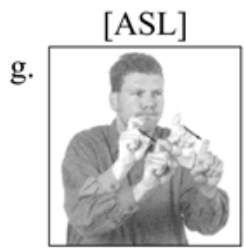

CL:bent animate

CL:bent animate

'two bent persons move forwards' d.

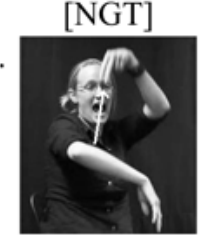

CL:long flat entity

CL:legged entity

'cat moves up

from plank'

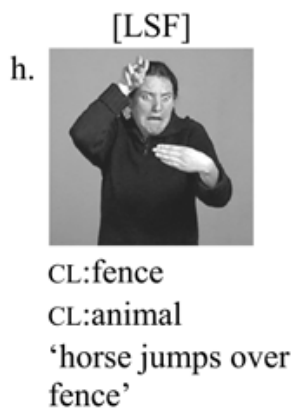

languages for which they have been reported. The future will show to what extent cross-linguistic differences exist.

Initially, classifier structures were considered mime-like and pantomimic, and their first descriptions were as visual imageries (e.g., DeMatteo 1977; Mandel 1977). Soon after that, however, these structures started to become analyzed as linguistic, morphologically complex signs. Notable is Supalla's $(1982,1986)$ seminal work on classifiers in ASL. Numerous studies of classifiers in various sign languages have been undertaken since.

Currently, classifiers are generally considered to be meaningful elements in morphologically complex structures, even though the complexity of these structures is not yet clear, and there is much controversy about the way in which they should be analyzed. The controversy is partly due to the fact that different studies use varying and sometimes unclear assumptions about the kinds of linguistic elements that classifiers in sign languages are, as well as about their function, and the types of constructions in which they occur. Space limitations do not allow extensive discussion of the various views. The main points in the literature will be explained and, where possible, related to the different views in order to obtain as much clarity as possible.

This chapter is structured as follows. The next section focuses on categories of classifiers in sign languages. This is followed by a section on classifier verbs. Section 4 discusses signs in which the classifiers can be recognized but differ in various respects from the classifier verbs that are the topic of section 3. Two sections follow with an 
overview of acquisition of classifiers in sign languages (section 5) and a comparison of classifiers in spoken and sign languages (section 6), respectively. Finally, section 7 contains some further considerations and conclusions.

\section{Classifiers and classifier categories}

The start of the study of classifiers in sign languages coincided with (renewed) interest in classifiers in spoken languages. Research of the latter traditionally focused on the semantics of classifiers, i.e. studies were made on the assignment of nouns to particular classes, in order to understand the ways in which humans categorize the world around them. On the basis of these assignments, various categories were suggested according to which nouns are classified in different languages. In addition, different types of classifier languages (or systems) were suggested. An overview article of the characteristics, typology, and classification in 50 different classifier languages (Allan 1977) has had a large influence on research on sign language classifiers. First, (as will be further exemplified in section 6), sign languages seemed to fall into one of the four types of classifier languages suggested by Allan, viz. predicate classifier languages, where classifiers occur with verbs (in contrast to appearing with numerals, nouns, or in locative constructions as in Allan's other three types of classifier languages). Second, in the spoken language literature, several semantic dimensions were distinguished according to which nouns were classified, such as material (including animacy), shape, consistency, size, location, arrangement, and quanta (see Allan 1977; but also Denny 1979; Denny/Creider 1986; Adams 1986). Similarly, much of the initial work on sign language classifiers has focused on semantic classification.

\subsection{Classifier categories}

Supalla $(1982,1986)$ considers ASL a predicate classifier language in Allan's categorization and categorizes the classifiers of ASL into five main types, some of which are divided into subtypes:

1. Semantic classifiers, which represent nouns by some semantic characteristic of their referents (e.g., belonging to the class of humans, animals, or vehicles);

2. Size and Shape Specifiers (SASSes), which denote nouns according to the visualgeometric features of their referents. SASSes come in two subtypes:

- static SASSes, which consist of a handshape (or combination of two hands) that indicates the size/shape of an entity;

- tracing SASSes, which have a movement of the hand(s) that outlines an entity's size/shape, and in which the shape of the manual articulator denotes the dimensionality of that entity;

3. Instrumental classifiers, which also come in two types:

- instrumental hand classifiers, in which the hand represents a hand that holds and/or manipulates another entity; and

- tool classifiers, in which the hand represents a tool that is being manipulated; 
4. Bodypart classifiers: parts of the body represent themselves (e.g., hands, eyes) or limbs (e.g., hands, feet); and

5. A Body classifier: the body of the signer represents an animate entity.

This categorization is not only based on semantics (as in spoken language classifications), but also on different characteristics of the classifiers within each type (in contrast to studies on spoken language classifiers). Basically, SASSes classify referents with respect to their shape, Instrumental classifiers on the basis of their function as instruments/tools, and the Body classifier represents animate entities. In addition, SASSes and Instrumental classifiers are claimed to be morphologically complex, in contrast to Semantic classifiers, and Body classifiers are a special category because they cannot be combined with motion or location verbs, in contrast to classifiers of other types (e.g., Supalla 1982, 1986; Newport 1982; Schick 1990a).

Since then similar as well as new categorizations have been suggested for ASL and a number of other sign languages (see, amongst others, McDonald (1982), Liddell/ Johnson (1987), and Benedicto/Brentari (2004) for ASL; Johnston (1989) and Schembri (2001, 2003) for Australian Sign Language (Auslan); Corazza (1990) for Italian Sign Language (LIS); Brennan (1990a,b) for British Sign Language (BSL); Hilzensauer/ Skant (2001) for Austrian Sign Language (ÖGS); and Fischer (2000) for Japanese Sign Language (NS)), and the categories have received various different terms. There is some overlap between them, which shows that the categorizations are problematic. This is important because the suggested categories have a large impact on the interpretation of classifiers and the structures in which they occur.

Currently two main categories of classifiers are distinguished, called 'Whole Entity classifiers' and 'Handling classifiers'. The first category contains classifiers that directly represent referents, by denoting particular semantic and/or shape features. By and large, this category comprises Supalla's Semantic classifiers, static SASSes, some Bodypart classifiers, and Tool classifiers. In the category of Handling classifiers we find classifiers that represent entities that are being held and/or moved; often (but not exclusively) by a human agent. This category contains classifiers that were previously categorized as Instrumental classifiers and some Bodypart classifiers.

Examples of Whole Entity classifiers (WECL) and Handling classifiers ( $H C L$ ) from TID and DGS, are shown in (2) and (3), where the manual articulator represents a flattish entity (a book) and a cylindrical entity (a mug), respectively. In (2a) and (3a), Whole Entity classifiers are used for these entities - the hands directly represent the

(2) a.

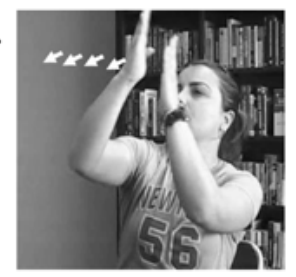

LH: WECL:flat entity

RH: WECL:flat entity

'There are books (in the book case).' b.

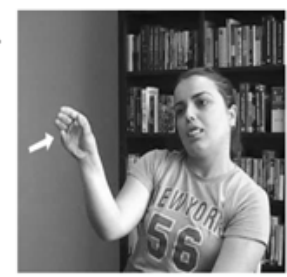

LH:

RH: HCL:flat (thick) entity

'(He) takes a book (from the book case).' 
(3) a.

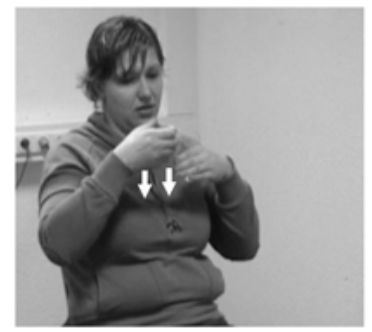

LH:

RH: WECL:cylindrical entities

'There are two mugs (on a tray).' b.

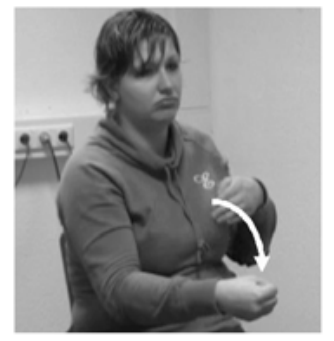

LH:

RH: HCL:entity with handle

'(He) puts one mug (on the table).'

entities; Handling classifiers are used for the same entities in (2b) and (3b), the hands indicating that the entities are held in the hand.

The Body classifier category proposed by Supalla $(1982,1986)$, which consists of only one element (the only classifier that is not represented phonologically by a configuration of the manual articulator but by the signer's body), is currently no longer considered a classifier by most researchers but a means for referential shift (e.g., Engberg-Pedersen 1995; Morgan/Woll 2003; see also chapter 17 on utterance reports and constructed action).

Although some researchers still count the category of tracing SASSes (viz. the subset of elements that consist of a tracing movement and a manual articulator, see (4)) among the classifiers, these differ in various aspects from all other classifiers. In contrast to other classifiers, tracing SASSes (i) are not expressed by a mere hand configuration, they also need the tracing movement to indicate the shape of the referent; (ii) they cannot be combined with verbs of motion; (iii) they denote specific shape information (in fact all kinds of shapes can be outlined, from square to star-shaped to Italyshaped); and, most importantly, (iv) they can be used in a variety of syntactic contexts: they appear as nouns, adjectives, and (ad)verbs, and do not seem to be used anaphorically (as will be exemplified in the next section). For these reasons, tracing SASSes are better placed outside the domain of classifiers.

Thus, ASL and most other sign languages researched to date can be argued to have two main categories of classifiers: Whole Entity classifiers and Handling classifiers. This categorization is not exactly based on the semantics of the units, but rather on their function in the grammar, which will be discussed in more detail in section 4 . Evidence from syntax and discourse will be given to sustain the necessity to distinguish these two types.

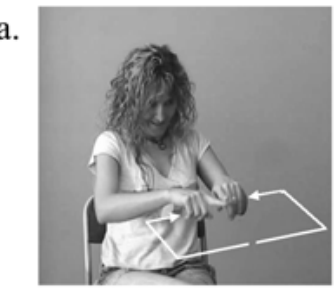

'rectangle'
[TID]

b.

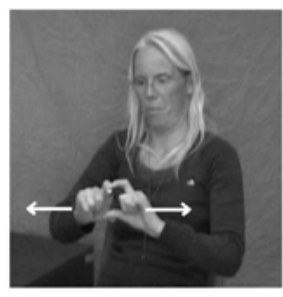

'stripe' 


\subsection{Classifiers: forms, denotation, and variation}

Entities are categorized according to semantic dimensions, as in spoken languages. Material (viz. animacy) and shape appear to be outstanding in all the sign languages that have classifiers. As for Whole Entity classifiers, most sign languages appear to have separate classifiers for animate entities, although the forms of the classifiers may differ. There is a -form (e.g., in ASL, NGT, DGS, DSL, and Auslan), and a has been reported in e.g., HKSL, Taiwan Sign Language, and Thai Sign Language. Some languages also have a -form for animate entities (e.g. DSL). Many sign languages have a classifier for legged entities (including humans and animals); represented by a ${ }^{2}$-form (a variant is the form with bent fingers बe, mostly used for animals). Some languages have a special classifier for vehicles, viz. ASL $(\approx)$, LiU (छ). However, some of the classifiers mentioned here may not be restricted to a particular class, for example vehicles, but may also include other types of entities, e.g. the vehicle classifier reported in some languages () may also include wide, flattish entities. Many sign languages

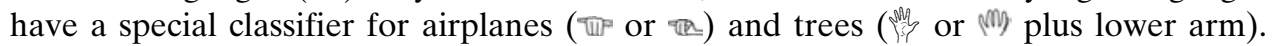
Most sign languages have rather extensive sets of classifiers denoting shapes: long and thin, solid, round (of various sizes), flat, cylindrical, bulky, tiny - and some even have a classifier for square entities (e.g., TID; see (1b)). All these shape-denoting classifiers are formed by varied numbers of extended, spread and/or bent fingers. Some researchers (such as Supalla 1982, 1986; Newport 1982; Schick 1990a,b) assume that these classifiers are themselves morphologically complex; each finger forms a separate morpheme. Some sign languages are reported to have default or general classifiers (e.g., a form where the tip of the index finger is important) that do not denote any characteristic of an entity, or a flat form (e.g., NGT, ASL, and HKSL). Examples of classifiers from various sign languages were shown in (1)-(3). Few classifier inventories are available; many available classifier studies focus on explanations of the denotations and properties of the classifiers and use a subset of the classifier forms to illustrate these. It is therefore not quite possible to indicate the variety and the extent of the sets of classifiers in various sign languages.

What becomes clear from the literature is that signers in most sign languages can use more than one classifier to represent a particular entity, in order to focus on a particular (different) characteristic of that entity (or to defocus it). For instance, a person can be represented with a classifier for animate entities, but a legs classifier will be used when the focus is on a person standing, or on the manner of locomotion (walking, sliding). A plate or a CD can be represented by a flat form ( ) but also by a round form (2). A car can be represented by a specific vehicle classifier in some sign languages, but signers may also choose to use a flat form (-), for example when indicating that there is something on top of the car (by placing another classifier on top of the classifier representing the car).

The sets of Handling classifiers in the various languages seem so far to be quite similar, although full inventories of these classifiers are not often provided. The form of these classifiers indicates the shape of an entity by the way in which it is held, e.g. thin or tiny entities are often represented by a -form, long and thin entities as well as entities that are held by a kind of handle use a 3 -form. Cylindrical entities are held with a श-form, flattish entities are held with a ๆ-form, thicker ones with a 5 -form, and bulkier entities with one or two $€$-forms. A signer can choose to use a special 
form when the entity is held in a different way than normal, e.g. because handling needs (more) force or the signer indicates that an entity requires controlled or delicate handling, as when it is fragile or filthy. Although the manual articulator usually represents the hand of a human agent holding an entity, in some cases the manipulator is not a human agent, but, for example, a hook or a grabber. It is possible to indicate the

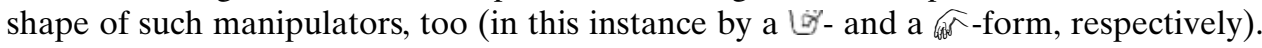

Thus, many sign languages share sets of classifier forms, but there are also languagespecific forms. In Whole Entity classifiers these forms often denote material and shape characteristics. In both classifier categories, some variation in the choice of a classifier is possible, which serves to focus on particular aspects of the referent.

\section{Classifier verbs}

For a good understanding, linguistic elements need to be investigated in linguistic contexts. Classifiers in sign languages often occur in combination with verbs, specifically verbs that indicate (i) a referent's motion through space, a change of posture, and its location or existence somewhere in space, and (ii) the handling of referents (Supalla 1982, 1986; Schembri 2001; Engberg-Pedersen 1993; Wallin 1996, 2000; Tang 2003; and many others). These, and particularly the first type of verbs, have been the focus of most of the research on classifiers in sign languages. Verb-classifier combinations bear a variety of terms in the literature (such as spatial-locative predicates, polymorphemic predicates/verbs, productive signs, highly iconic structures, i.e. transfers of situation, to mention a few). The terms used often reflect a particular view on the structure of these combinations. In this chapter, they will be referred to as 'classifier verbs'. Studies vary with respect to what they consider as classifier verbs. For example, verbs of geometrical description (or tracing SASSes) that are made at particular locations in space are sometimes counted among the classifier verbs; sometimes verbs expressing the manner of locomotion are included, and some studies do not restrict the occurrence of classifiers to motion verbs but also include other verbs in which the manual articulator is meaningful. Different analyses of classifiers and classifier verbs result. We will focus here on verbs that express a directed motion of a referent through space, a change of posture of a referent, the localization of a referent in sign space, and the existence of a referent at a location in sign space, for both Whole Entity and Handling classifiers.

Let us look at a typical example of classifier verbs in context from ASL in (5) (from Emmorey 2002, 87): In such structures, a referent is initially introduced by a noun, then followed by a verb with a classifier representing the referent of the noun (signs 1 and 3 introduce a referent and signs 2 and 4 contain classifier verbs). If more than one referent is represented in space, the bigger/backgrounded entity is introduced first (the 'Ground' in the literature on language and space, e.g., Talmy 1985), and then the smaller entity, which is in the focus of attention (the 'Figure'). The simultaneous representation of the referents in a classifier construction, the particular positioning of which expresses the spatial relation between the referents, is reported to be obligatory in some sign languages (see Supalla 1982; Perniss 2007; Morgan/Woll 2008; Chang/Su/Tai 2005; and Tang/Sze/Lam 2007). In the following sections, we will focus on the structure of classifier verbs. 
(5)

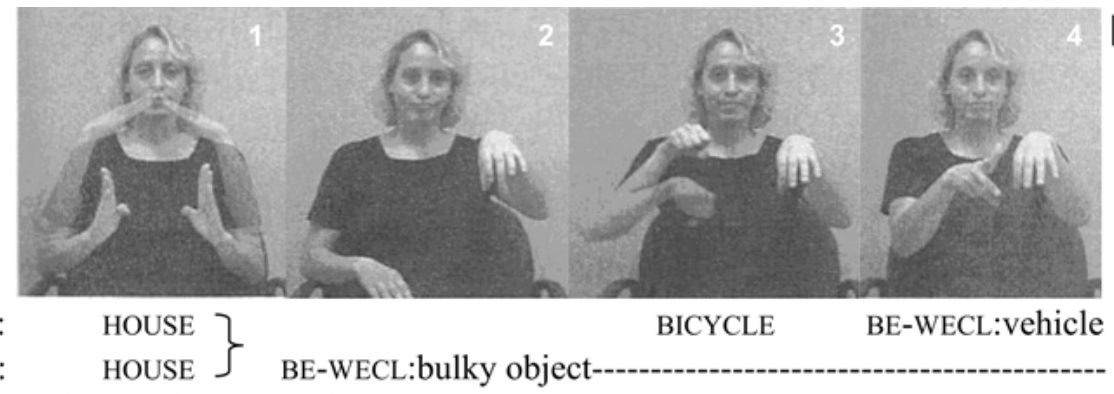

LH:

RH: HOUSE $\}$ BE-WECL:bulky object

'A bicycle is near the house.'

\subsection{The matter of morphological complexity of classifier verbs}

The morphological structure of classifier verbs is rather underinvestigated, which is surprising in view of the fact that sign languages are generally claimed to have complex morphology, and classifier verb formation is considered a very productive process. Supalla's $(1982,1986)$ work gives an extensive morphological analysis of classifier verbs. A classifier verb, in his view, is one (or a combination) of a small subset of verb roots, which can be combined with large numbers of affixes. The most prominent of these affixes is the classifier, that he considers an agreement marker for a noun argument of the verb root. Some classifiers are morphologically complex. They can be combined with orientation affixes as well as affixes indicating how the referent is affected (e.g., 'wrecked' or 'broken'). The verb root can, furthermore, be combined with various manner and placement affixes. In Supalla's analysis (and in others to follow), sign parameters that in other signs are considered mere phoneme values are morphemic as well as phonemic. Unfortunately, no complex signs with complete morphological analysis are provided in Supalla's work, nor are considerations given as to why particular parts of signs have a particular morphological status rather than another (or are not morphemic at all).

Supalla's analysis has been criticized as being too complex, since he considers every aspect of the signs under discussion that might contribute meaning to the whole as morphemic. As a result, the suggested morphological structure is huge in view of the fact that classifier verbs enhance multiple aspects of motion and location events, especially in comparison to spoken languages (even spoken languages that are renowned for their morphological complexity). Liddell (2003, 204-206) attempts to give a morphological analysis of a two-handed classifier construction (glossed as PERSON $_{\mathrm{I}}$-WALKTO-PERSON 2 ) based on the morphemes suggested by Supalla and counts four roots and minimally 14 and maximally 24 affixes in this sign. This shows that Supalla's morphological analysis of these verbs is indeed extremely complex, but also that it is not detailed enough since the morpheme status of ten aspects in this particular sign is not clear. One can, therefore, wonder whether too much morphology was assumed and whether some aspects of these structures can be accounted for without necessarily assigning them morphological value. Nevertheless, at least parts of Supalla's analysis hold valid for many researchers: it is generally assumed that at least the movements/ locations and the manual articulator are meaningful. The analyses of the morphological 
structure of such verbs differ, however. Liddell (2003), for example, presents the view that although the articulator and movement may be morphemes in such verbs, the process by which the verbs are formed is not very productive, and in many verbs that, at first sight, contain meaningful manual articulators and meaningful movements, these sign parts behave idiosyncratically and are not productively combined with other sign parts to form new structures. McDonald (1982) and Engberg-Pedersen (1993) observe that the interpretation of classifier verbs seems to be in part dependent on the classifier that is used. Engberg-Pedersen (1993) furthermore points out that particular movements do not combine well with particular classifiers and suggests that the classifier is the core element in these structures rather than the movement (although no further claims are made with respect to the morphological status or structure of the verbs). Slobin et al. (2003) suggest that classifier verbs may be similar to bipartite verb stems in spoken languages (e.g., Klamath; Delancey 1999), in which the contribution of classifier and movement (and other) components is of equal importance in the complex verb. Many studies, however, merely indicate that the classifier and the movement are morphemes, although it is generally assumed that other aspects of the classifier verb that convey information about the event (such as manner of locomotion and locations) are (or at least can be) expressed by morphemes. More detailed discussion of the structure of the sign is usually not given. Still, all studies agree that these constructions are verbs, referring to an event or state in the real world.

It is recognized in most investigations that there is an anaphoric relation between the classifier and the referent that is involved in the event. As stated in the previous section, the referent is usually introduced before the classifier verb is sign, although in some cases the referent is clear from the (previous or physical) context and need not be mentioned. After introduction of the referent, it can be left unexpressed in the further discourse (e.g. in narratives) since the classifier on the verb suffices to track the referent involved. The relation is deemed systematic. Supalla (1982) and some of the subsequent researches (e.g., Benedicto/Brentari 2004; Chang/Su/Tai 2005; Cuxac 2003; Glück/Pfau 1998, 1999; Zwitserlood 2003, 2008), consider the classifier an agreement marker or a proform for the referent on the verb. In these accounts, the movement (or localization) in the sign is considered a verb root or stem, and the classifier as well as the locus in space as functional elements (i.e. inflectional affixes). These views will be discussed in more detail in the next section.

\subsection{Verb roots, (in)transitivity, and the classifier category}

As was stated in section 2, researchers generally distinguish two main categories of classifiers: Whole Entity classifiers and Handling classifiers. The first are seen in verbs that express a motion of a referent, its localization in space, or its existence in space. In these verbs, the classifiers represent the referent directly. Handling classifiers, in contrast, occur with verbs that show the manipulated motion or the holding of a referent. The contrast between the two has already been shown in (2) and (3), and is further illustrated in (6), from DGS.

The signer uses two verbs with Whole Entity classifiers (hin in signs 13 and 15) and

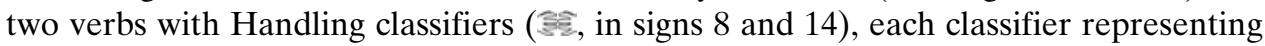
the old woman. When he uses the verbs with Whole Entity classifiers, he describes an 
(6)

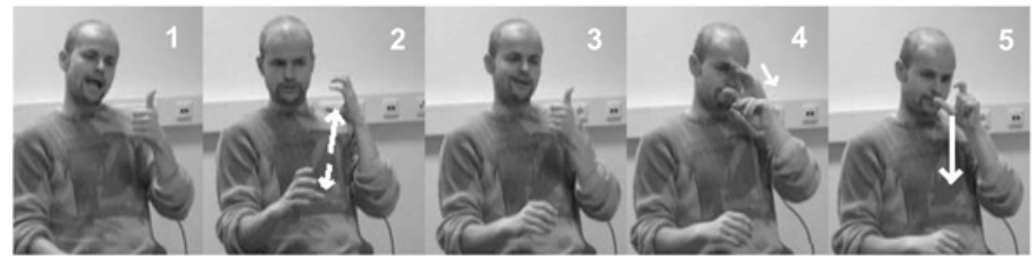

[DGS]

LH:

BUS

RH: ONE BUS

ONE

MAN

PERSON

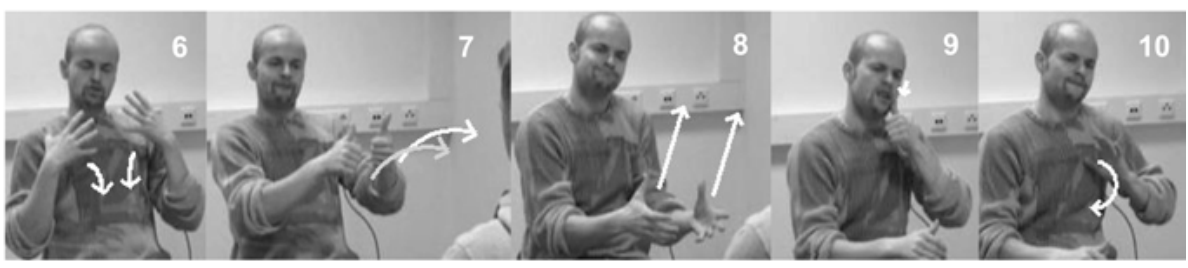

LH: BLACK-CLOTHES HELP

LIFT-HCL:cyl. entity

RH: BLACK-CLOTHES HELP LIFT-HCL:cyl. entity

OLD

WOMAN

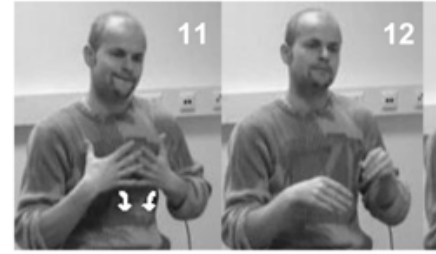

LH: WHITE-CLOTHES

RH: WHITE-CLOTHES WITH
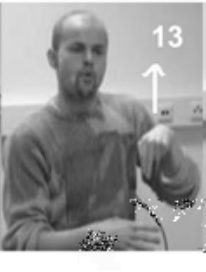

MOVE.UPWECL:legs

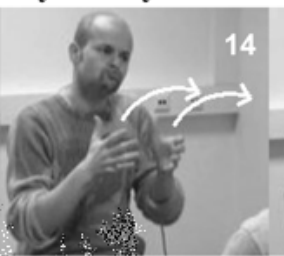

PUT-HCL:Cyl.entity

PUT-HCL:cyllentity get.on-WECL:legs

independent motion of the woman, who wants to move up, onto the bus, and the Handling classifiers are used for a manipulated motion of the old woman by a human agent (the man). There is a close connection between the category of classifier and the transitivity of the verb: Whole Entity classifiers occur with intransitive verbs, whereas Handling classifiers are used with transitive verbs (in chapter 19, the use of classifier types is discussed in connection with signer's perspective; see also Perniss 2007). Following Supalla (1982), Glück and Pfau (1998, 1999), Zwitserlood (2003), and Benedicto and Brentari (2004), consider the classifier in these verbs as a functional element: an agreement marker, which functions in addition to agreement by use of loci in sign space (see chapters 7 and 10 for details on agreement marking by loci in sign space). Benedicto and Brentari (2004) furthermore claim that the classifier that is attached to the verb is also responsible for its (in)transitivity: a Handling Classifier turns a (basically intransitive) verb into a transitive verb.

The analysis of classifiers as agreement markers is not uncontroversial. Counterarguments are given by observations that classifiers are not obligatory (as they should be if they were agreement markers), and that there is variability in the choice of a classifier (as discussed in section 2.2), which should not be possible if classifiers were agreement markers. These arguments, however, are not valid. First, marking of agreement is not obligatory in many languages in the world that can have agreement mark- 
ing (Corbett 2006). Second, and connected to the first point, the fact that classifiers do not occur with verbs other than verbs of motion and location verbs may have phonological/articulatory reasons: it is not possible to add a morpheme expressed by a particular configuration of the manual articulator to a verb that already has phonological features for that articulator. This is only possible with verbs that have no phonological specification for the manual articulator, i.e. motion and location verbs (in the same vein it is argued that many plain verbs cannot show agreement by loci in sign space because they are body anchored (i.e. phonologically specified for a location); see also chapter 7 on agreement).

Finally, variability in the choice of a classifier is, in part, the result of the verb's valence: a different classifier will be combined with an intransitive and a transitive verb: Whole Entity classifiers appear on intransitive verbs, and transitive ones will be combined with Handling classifiers. Also, some variability in choice of agreement markers is also observed in other (spoken) languages. This issue, however, is still under debate.

\subsection{The phonological representation of the morphemes in classifier verbs}

Classifiers in sign languages are often described as bound morphemes, i.e. affixes (see, among others, Supalla 1982; Meir 2001; Tang 2003; Zwitserlood 2003). They are generally considered to be expressed by a particular shape of the manual articulator, possibly combined with orientation features. Classifiers thus lack phonological features for place of articulation and/or movement. It may be partly for this reason that they are bound. Researchers differ with respect to their phonological analysis of the verbs with which classifiers occur. In some accounts (e.g., Meir 2001; Zwitserlood 2003, 2008), classifier verbs contain a root that only has phonological specifications for movement (or location) features, not for the manual articulator. Classifier verb roots and classifiers, then, complement each other in phonological specification, and for this reason simultaneous combination of a root and a classifier is always possible. In other accounts (e.g., Glück/Pfau 1998, 1999), verbs are assumed to be phonologically specified for movement and handshape features. The affixation of a classifier triggers a phonological readjustment rule for handshape features, which results in a modification of the verbal stem.

Some attention has been given to the apparent violations of well-formedness constraints that classifier verbs can give rise to (e.g., Aronoff et al. 2003, 70f). It has also been observed that classifier verbs are mostly monosyllabic. However, apart from Benedicto and Brentari (2004), there have been no accounts of phonological feature specifications of classifiers and classifier verbs; in general classifiers are referred to as 'handshapes'. Recent phonological models (e.g., Brentari 1998; van der Kooij 2002) as well as new work on phonology may be extended to include classifier verbs.

To sum up, there are a few studies with argued suggestions for a (partial) morphological structure of classifier verbs. In general, these signs are considered as verb roots or verb stems that are combined with other material; classifiers are argued to be separate morphemes, although the status of these morphemes is still a debated issue. They 
are not specified, or claimed to be roots or affixes (e.g., agreement markers). Handling classifiers occur in transitive classifier verbs, where the classifier represents a referent that is being held/manipulated (as well as a referent that holds/manipulates the other referent); Whole Entity classifiers, in contrast, occur in intransitive verbs and represent referents that move independently of manipulation or simply exist at particular locations in sign space. Phonological representation of classifier verbs in sign languages has received little attention to date.

\section{Classifiers in signs other than classifier verbs}

Not only do classifier verbs contain meaningful manual articulators; they are also encountered in other signs. Some examples from NGT are shown in (7), in which we recognize the hand configuration representing long and thin entities, i.e. knitting needles, legs, rockets, and thermometers ( for manipulation of long and/or thin entities (with control), such as keys, fishing rods, toothbrushes, and curtains (\$)):

a.

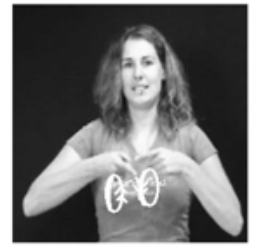

'to knit'

e.

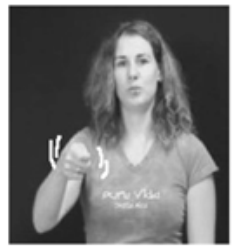

'key' b.

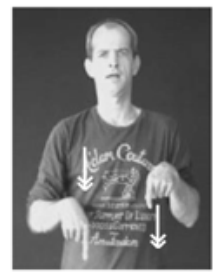

'handicap'

f.

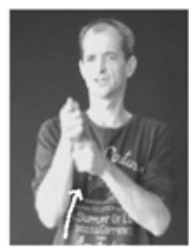

'to fish' c.

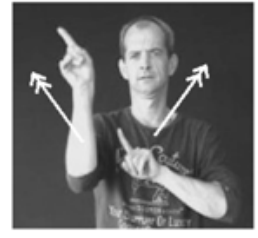

'fireworks'

g.

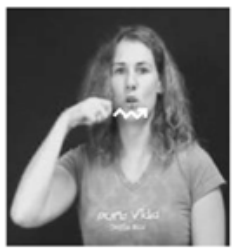

'to brush teeth' d.

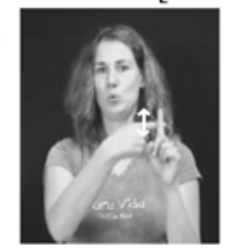

'temperature'

h.

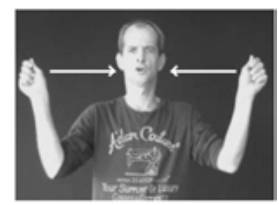

'curtains'

There are different views of the structure of such signs, as explained below: some researchers consider them monomorphemic, while others claim that they are morphologically complex. These views are discussed in the next section.

\subsection{Complex or monomorphemic signs?}

Traditionally, signs in which the manual articulator (and other parameters) are meaningful, but which are not classifier verbs, are called 'frozen' signs. This term can be 
interpreted widely, for example as 'signs that are monomorphemic', 'signs that one may find in a dictionary', and 'signs that may be morphologically complex but are idiosyncratic in meaning and structure'. Most researchers adhere to the view that these signs originate from classifier verbs that have been formed according to productive sign formation processes, and that have undergone a process of lexicalization (e.g., Supalla 1980; Engberg-Pedersen 1993; Aronoff et al. 2003), i.e. the interpretation of the sign has become more general than the classifier verb, and the hand configuration, location, and movement parts no longer have distinct meanings, and therefore can no longer be interchanged with other parts without radically changing the meaning of the whole sign (in contrast to classifier verbs). Often the signs do not express (motion or location) events any more, in contrast to classifier verbs (e.g., Supalla 1980; Newport 1982), they obey particular phonological restrictions that can be violated by classifier verbs, and they can undergo various morphological processes that are not applicable to classifier verbs, such as affixation of aspectual markers (Sandler/Lillo-Martin 2006; Wilbur 2008) and noun derivation affixes (Brentari/Padden 2001).

There are also studies claiming that many such signs are not (fully) 'frozen', but, on the contrary, morphologically complex. In some studies it is implied that sign language users are aware of the meaningfulness of parts of such signs, such as the handshape (Brentari/Goldsmith 1993; Cuxac 2003; Grote/Linz 2004; Tang/Sze/Lam 2007; Sandler/Lillo-Martin 2006). Some researchers suggest that such signs are actually the result of productive processes of sign formation (e.g., Kegl/Schley 1986; Brennan 1990a,b; Johnston/Schembri 1999; Zeshan 2003; Zwitserlood 2003, 2008). Signers of various sign languages are reported to coin new signs on the spot when they need them, for instance when the language does not have a conventional sign for the concept they want to express or when they cannot remember the sign for a particular concept, and these signs are usually readily understood by their discourse partners. Some of these newly coined signs are accepted in the language community and become conventionalized. This does not necessarily mean that they started out as productively formed classifier constructions that are lexicalized in the conventionalization process (lexicalization in this context meaning: undergoing (severe) phonological, morphological, and semantic bleaching). Even though lexicalization as well as grammaticalization processes take place in all languages and sign languages are no exception, sign languages are relatively young (see chapter 34 on lexicalization and grammaticalization). In addition to the fact that there may be other sign formation processes besides classifier verb formation involved, it is not very plausible that diachronic lexicalization processes have taken place at such a large scale as to result in the large numbers of signs in which meaningful hand configurations occur (as well as other meaningful components) in many sign languages, especially in the younger ones. Besides this, it has not been possible to systematically verify the claim of diachronic lexicalization of signs for most sign languages because of a lack of well-documented historic sources.

Some phonological studies have recognized that the 'frozen' lexicon of sign languages contains many signs that may be morphologically complex. These studies recognize relations between form and meaning of signs and sign parts, but lack morphological accounts to which their phonological descriptions may be connected (Boyes Braem 1981; Taub 2001; van der Kooij 2002; see also chapter 18 for discussion of iconicity). 


\subsection{The structure of 'frozen' signs}

A few studies discuss the structure of 'frozen' signs; these are briefly sketched below (see chapter 5 for a variety of other morphological processes in sign languages). Brennan's $(1990 \mathrm{a}, \mathrm{b})$ work on sign formation in BSL is comprehensive and aims at the denotation of productively formed signs, i.e. the characteristic(s) of an entity or event that are denoted in such signs and the way in which this is done, especially focusing on the relation of form and movement of the manual articulator on the one hand and aspects of entities and events on the other. Although Brennan indicates that sign parts such as (changes of) hand configurations, movements, and locations are morphemes, she does not provide morphological analyses of the signs in which they appear. She roughly states that they are kinds of compounds, and distinguishes two types: simultaneous compounds and 'mix ' $\mathrm{n}$ ' match' signs. Brennan argues that simultaneous compounds are blends of two individual signs (many of which contain classifiers), each of which necessarily drops one or more of its phonological features in the compounding process, in order for the compound to be pronounceable. Mix ' $n$ ' match signs are combinations of classifiers, symbolic locations, and meaningful non-manual components. According to Brennan, the meaning of both types of sign is not always fully decomposable.

Meir (2001) argues that Israeli Sign Language (Israeli SL) has a group of noun roots (also called 'Instrumental classifiers') - free morphemes that are fully specified for phonological features, and that can undergo a lexical process of Noun Incorporation into verbs. This process is subject to the restriction that the phonological features of noun root and verb do not conflict. The output of this process is a compound. Examples of such compounds are the signs glossed as SPOON-FEED, FORK-EAT, NEEDLESEW, and SCISSORS-CUT. According to Meir, the differences between the processes and outputs of Noun Incorporation and classifier verb formation are the following: (i) the former are combinations of free morphemes (verb and noun roots) whereas the latter are combinations of verbs and affixes; (ii) combinations of classifier verbs and classifiers are always possible because their phonological features never conflict, whereas Noun Incorporation is blocked if the phonological features of the verb and noun root conflict; (iii) in the compounding process, the incorporated Noun root constitutes a syntactic argument, which cannot be expressed with a separate noun phrase in the sentence after incorporation, whereas after classifier verb formation, both the classifier representing a referent and the noun referring to that referent can be present in the sentence.

An analysis that is reminiscent of Brennan's (1990a,b) and Meir's (2001) work is provided in Zwitserlood $(2003,2008)$ for NGT. There it is argued that all manual sign parameters (handshape, orientation, movement, and location) can be morphemic (as in Brennan 1990a,b). All these morphemes are considered roots that are phonologically underspecified (in contrast to Meir's (2001) view) and that can combine into complex signs called 'root compounds'. Zwitserlood argues that the roots in these compounds do not have a grammatical category. The signs resulting from combinations of these roots are morphologically headless and have no grammatical category at first instance. The grammatical category is added in syntax, after the sign has been formed.

In this view, the differences between root compounds and classifier verbs, and the processes by which they are formed are the following: (i) the former is a lexical (com- 
pounding) process; the latter a grammatical (inflectional) process; (ii) classifier verbs consist of only one root that is phonologically specified for a movement. This root is assigned the grammatical category of verb in syntax, after which various affixes, such as the classifier (which is considered an agreement marker), are added. Root compounds, in contrast, contain more than one root, one of which may be a classifier, and they can be assigned different grammatical categories; (iii) the classifier in a classifier verb is always related to a syntactic argument of the verb, i.e. the Theme (moving) argument; the classifier in root compounds is not systematically related to a syntactic argument (in case the root compound is a verb); and (iv) whereas intransitive classifier verbs combine with Whole Entity classifiers and transitive ones with Handling classifiers in classifier verbs, a classifier in a verbal root compound is not connected with the verb's valence. Zwitserlood's account shows similarities to Brennan's work and shares some ideas with Meir's analysis. It is also somewhat reminiscent of the idea of bipartite (or rather, multipartite) stems suggested by Slobin et al. (2003), with the difference that the root compounding process is not restricted to verbs.

To summarize, although in most sign languages classifiers are recognized in many signs that are not classifier verbs, the morphological structure of these signs has been investigated only rarely to date. This is largely due to the fact that these signs are reminiscent of classifier verbs while they do not show the patterns and characteristics observed in constructions with classifier verbs. As a result, the signs in question are generally taken to be lexicalized forms without internal morphology. The literature contains a few studies that recognize the fact that classifiers as well as other sign parameters are used systematically and productively in new sign formation in many sign languages and that some of the signs thus formed enter the established lexicon (see also Johnston/Schembri 1999). Signers also appear to be sensitive to the meaningful elements within the signs. The general assumption that these signs are monomorphemic may be partly due to the gloss tradition in sign language research, where signs are labeled with a word or word combination from the local spoken language and/or English that often does not match the internal structure of the signs. Unintentionally, researchers may be influenced by the gloss and overlook sign-internal structure (see Hoiting/Slobin 2002; Zwitserlood 2003). There are several accounts of sign-internal morphology (e.g., Padden/Perlmutter 1987; Fernald/Napoli 2000; Frishberg/Gough 2000; Wilbur 2008; as well as others mentioned in this section) along the lines of which more morphological studies of signs and new sign coinage can be done. Also, psycholinguistic studies of sign processing are important in showing awareness of morphological structure in users of sign languages.

\section{The acquisition of classifiers in sign languages}

Chapter 28 of this volume gives a general overview of sign language acquisition. In addition, this section will focus particularly on research into the acquisition of classifier structures by Deaf children. Many of these studies concentrate on production of classifiers by Deaf children, i.e. on the age and the order in which they acquire the different classifiers in their target language. Mostly elicitation tasks are used (e.g., Supalla 1982; Kantor 1980; Schick 1990b; Fish et al. 2003). In a few studies, the movements within the classifier verbs are also taken into account (e.g., Newport 1988; Tang/Sze/Lam 2007). 
The children in these studies are generally aged three years and older, and the tasks are often designed to elicit Whole Entity classifiers (including SASSes), although studies by Schick (1990b) and Slobin et al. (2003) also look at Handling classifiers. All studies are cross-sectional.

\subsection{Production studies}

The general results of the production studies are that the youngest children initially use different strategies in expressing the events presented in the stimuli. They use lexical verbs of motion as well as classifier verbs, and sometimes they do not use a verb at all. Older children use more classifier verbs than younger children. Although the classifiers used by these children are often quite iconic, children initially do not seem to make use of the possibility of iconic mapping that most sign languages offer between motion events and spatial situations in real life on the one hand, and the use of space and iconic classifier forms on the other (but see Slobin et al. (2003) for arguments for iconic mapping in spontaneous (possibly gestural) utterances by children between one and four years of age). As for the movements within the verbs, children seem to represent complex path movements sequentially rather than simultaneously, unlike adults (Supalla 1982; Newport 1988). Young children often use a general classifier instead of a more specific one or a classifier that is easier to articulate than the target classifier (e.g., 解 instead of the 5 -form representing vehicles in ASL). Nevertheless, target classifiers that are considered motorically simple are not always acquired earlier than those that are more complex (note that it is not always clear which handshapes are simple and which are complex). In many cases where the spatial scene to be described contains a Figure and a Ground object, children do not represent the Ground referent simultaneously with the Figure referent, while in some cases in which the Ground referent is present, it is not appropriate (e.g., the scale between the Ground and the Figure referents is not felicitous). The correct use of classifiers is not mastered before eight to nine years of age.

The conclusions of the studies are not unequivocal. In some studies (even studies of acquisition of the same target language) the children appear to have acquired a particular classifier earlier than in others, or a particular classifier category has been acquired earlier than stated in another study (e.g., Tang/Sze/Lam 2003). Many researchers indicate that young children rarely use complex classifier constructions, i.e. constructions in which each hand represents a different entity. Studies that discuss errors that are made by the children provide an interesting outlook on their development, for example apparent overgeneralization of morphological structure in lexical signs (e.g., Bernardino 2006; Tang/Sze/Lam 2007).

\subsection{Comprehension studies}

Few comprehension studies of acquisition of classifier constructions in sign languages have been undertaken to date. The existing studies focus on comprehension of the motions and (relative) locations of referents in (intransitive) classifier verbs, rather 
than on the classifier handshapes. For BSL, Morgan et al. (2008) conclude that verbs containing path movements are better and earlier understood than those containing localizations, and that both movements and localizations are not yet mastered at five years of age. Martin and Sera (2006) report that comprehension of locative relations between referents (both static and dynamic) is still not fully acquired by children learning ASL at nine years of age.

\subsection{Interpretation of the results}

Because of the different approaches, the studies cannot easily be compared, and interpretation of the results of the available acquisition studies is rather difficult. More importantly, the results are somewhat obscured by the different assumptions about the structures under research which underlie the designs and scorings. For example, although the term 'SASS' is used in several studies, what the term covers is not described in detail; therefore its interpretation may differ in these studies. Also, from descriptions of test items it appears that these may involve classifier verbs as well as verbs that do not express a motion or location of a referent (such as signs for looking and cutting). One of the most important issues in this respect is the fact that in most studies vital information is missing about the targets of the test items. Thus, it is often unclear how these were set and how the children's data were scored with respect to them. Since adult language is the target for the children acquiring the language, language use and comprehension of adults should be the target in acquisition tests. It can be seen in a few studies (e.g., Fish et al. 2003) that the children's classifier choices for referents show variation, some of which indicates a particular focus on the referent. However, it is not clear how this is related to adult variation on these test items. For instance, Martin and Sera (2006) compared comprehension of spatial relations by children acquiring ASL and children acquiring English, in which the children's scores were also compared to adult scores on the same test items (in ASL and English). As expected, the English-speaking adults scored $99 \%$ correct. However, the ASL using adults had a mere $78 \%$ mean correct score. Apparently, in this case the test targets were not the adult patterns, and it is unclear, therefore, what patterns were selected as targets. This also holds for most other classifier acquisition studies.

\subsection{Summary}

Research shows that the acquisition of classifier constructions in sign languages is a very complex task, in which the child makes little use of the iconic mapping between event and linguistic representation. Correct use of classifier verbs is not fully acquired until children are in their early teens. Further research with broader scope, taking context, different strategies, and variation in the choice of classifier into account and clearly relating the results to adult comprehension and performance is necessary to shed more light on the acquisition of these constructions. 


\section{Classifiers in spoken and sign languages: a comparison}

\subsection{Overview of recent research on spoken language classifiers}

Research into classifiers in spoken languages began well in the 1970s. It became clear that there are different classifier systems in the world's languages. As stated in section 2, early study of sign language classifiers was much influenced by the then available literature on spoken language classifiers. In an overview article by Allan (1977) languages with classifiers were distinguished into four types, one of which is a 'predicate classifier language' (e.g., Navajo). Classifiers in sign languages seemed to match this type, and similar structures in Navajo and ASL were used to exemplify this. However, the comparison does not hold on two points: first, Navajo is a language with classificatory verbs rather than classifier verbs, the difference being that in classifier verbs a separate verb stem and classifier can be distinguished, while in classificatory verbs the verb stem itself is responsible for classification of the referent involved in the event and no separate classifying morpheme can be discerned (Young/Morgan 1987; Aikhenvald 2000; Grinevald 2000). Second, and related to the previous point, the early comparisons between structures in Navajo and ASL were based on misinterpretation of the Navajo classificatory verbs (Engberg-Pedersen 1993; Schembri 2001; Zwitserlood 1996, 2003).

Recent studies, particularly work by Aikhenvald (2000) and Grinevald (2000) give much more, and newer, information about classifiers in a variety of spoken languages, covering their semantics, pragmatics, function, and morphological realization. If we take as a premise that a classifier be a distinct morpheme, four major categories of classifiers can be distinguished (which are not quite the same as those suggested by Allan (1977)). These have the following characteristics:

1) Noun classifiers are free morphemes that occur within a noun phrase (more than one classifier may occur within the noun phrase). The noun classifiers' semantics are often based on animacy and physical properties of the referent. The choice of a noun classifier is based on semantics and can vary, when a speaker focuses on different characteristics of the noun referent. Not all nouns in a language take a classifier. The sets of noun classifiers in different languages can vary from small (even two, e.g. in Emmi, Australia) to (very) large (several hundreds in Asian languages). These classifiers function as determiners but can also be used pronominally (in which case the NP does not contain a noun).

2) Numeral classifiers are free or bound morphemes that are obligatory in numeral and quantified noun phrases. They also occur occasionally with adjectives and demonstratives. The semantics of these classifiers includes animacy, social status, directionality, and physical and functional properties. The choice of a numeral classifier is predominantly semantic and some nouns have alternative choices of classifiers, depending on the property of the noun that is in focus. Every noun with a countable referent has a classifier, although there may be some abstract nouns that are not classified. The number of classifiers may range from few (e.g., 14 in Tashkent, Uzbek) to large numbers (e.g., an estimate of 200 in Thai and Burmese). Their main function is to individuate nouns (typically 'concept' or mass nouns in 
the languages with this classifier system) in a quantificational environment, but they can also have an anaphoric function.

3) Genitive (or: possessive or relational) classifiers are bound morphemes that occur in noun phrases with possessive constructions. They generally refer to the semantic class of the possessed nouns. Not all nouns are categorized by a classifier; nouns that are classified often belong to a particular semantic group. The semantics concerns physical and functional properties, nature, and sometimes animacy. Some languages with a system of genitive classifiers have a 'generic' or 'default' classifier that can be used instead of more specific ones. This type of classifier can consist of independent words or affixes. The choice of a classifier is strictly semantic and the size of the classifier inventories is variable. The function of this type of classifier is the expression of possession.

4) Verbal classifiers are bound morphemes that are affixed to verbs and are linked to verb arguments (usually subjects or objects, but sometimes even peripheral arguments), in terms of their inherent properties. The semantics of these classifiers has a wide range, usually based on physical and functional properties, nature, directionality/orientation, quanta, and sometimes animacy. The number of classifiers ranges from several dozen (e.g., Terena, a language spoken in Brazil) to over one hundred (e.g., Mundurukú, a Tupi language of north central Brazil). Usually only a subset of verbs in a language takes a classifier. Not all nouns are classified, but a noun can have more than one classifier. The main function of this type of classifier is referent tracking.

A note of caution is needed here: the characteristics of the classifier systems outlined above are generalizations, based on descriptions of (large) sets of data from languages that employ one or more of these classifier systems. There is, however, much variation within the systems. Also, some classifier systems have been well studied, whereas others, particularly verbal classifier systems, are still under-researched in comparison to other systems (such as numeral classifiers), which complicates a comparison between classifier systems in spoken and sign languages considerably.

\subsection{A comparison between (verbal) classifiers in spoken and sign languages}

As stated in section 3, classifiers in sign languages typically occur on verbs. Thus, a comparison between sign and spoken languages should focus primarily on verbal classifiers. Classifiers in sign languages share a number of characteristics with verbal classifiers in spoken languages. In some characteristics, however, they differ. We will now focus on the main characteristics of classifiers in both modalities and discuss their similarities and differences.

First, verbal classifiers are affixes attached to a verb stem (Aikhenvald 2000, 428; Grinevald 2000, 67). For example, in the Australian language Gunwinggu the classifier bo: (for liquid referents) is bound to the verb stem mangan ('fall') (Oates 1964, in Mithun 1986, 389): 


$$
\begin{aligned}
& \text { gugu ga- bo:- mangan } \\
& \text { water it- cL:liquid- fall } \\
& \text { 'Water is falling.' }
\end{aligned}
$$

[Gunwinggu]

Classifiers in sign languages are also considered as affixes by many researchers (e.g., Supalla 1982, 24; Sandler/Lillo-Martin 2006, 77), while others do not specify their morphological status.

Second, verbal classifiers in spoken languages are linked to the subject or object argument of the verb to which they are affixed and they are used to maintain reference with the referent throughout a discourse (Aikhenvald 2000, 149). The verb determines which argument the classifier represents: the classifiers represent the subject in intransitive verbs and the object in transitive verbs. This is illustrated with the classifier $n$ for round entities in the North Athabaskan language Koyukon, which represents a rope. The rope is the subject of the intransitive verb in (9a) and the object of the transitive verb in (9b) (Thompson 1993, in Aikhenvald 2000, 168):
a. tl'oel n-
aal'onh
rope CL:round.thing- be.there
'A rope is there.'
b. tloel n- aan- s- 'onh
rope CL:round.thing- PREF- 1SG- arrive.carrying
'I arrived carrying a rope.'

[Koyukon]

As we have seen in examples (5) and (6) in section 3, a signer can use a classifier after its referent has been introduced (or when it is clear from the context), to relate the referent's motions through space, a change in its posture, or its existence and/or location in sign space. The classifier suffices to maintain the reference through long stretches of discourse, and thus no overt nouns are necessary (though they may they still occur, e.g. to re-establish reference). Thus, similarly to verbal classifiers in spoken languages, classifiers in sign languages function as referent tracking devices. Some researchers claim that classifiers represent verb arguments and function as agreement markers of the arguments on the verbs. A difference between the two modalities is that there are generally no separate classifiers for transitive and intransitive verbs in spoken languages, whereas such a difference is found in sign languages: Whole Entity classifiers appearing on intransitive verbs versus Handling classifiers that appear on transitive verbs.

Third, although verbal classifiers in spoken languages have an anaphoric function, their use is not obligatory. They typically occur on a subset of a language's verbs, and are sometimes used for special effects (e.g., stressing that a referent is completely involved in the event in Palikur (an Arawak language used at the mouth of the Amazon river), as stated by Aikhenvald $(2000,165))$. This characteristic is rather difficult to compare with classifiers in sign languages. Apparently classifiers in sign languages only occur on a subset of verbs, but this may be a result of the articulatory possibilities of the manual-visual modality as described above in sections 3.3 and 4.2. Classifiers in sign languages can only co-occur with verbs that do not have phonological specifications for the manual articulator (usually verbs of motion and location), not on verbs that have inherent phonological specifications for the hand. It is interesting, though, that verbs 
that take classifiers in spoken languages are also often motion verbs, positional verbs, verbs expressing the handling of an object, as well as verbs that describe physical properties of the referent. Whether or not sign language classifiers are obligatory on the subset of motion/location verbs is still a matter of debate. For example the fingertip that is sometimes used for localization of referents in space or for tracing the motion of a referent through space is regarded by some as a kind of 'default' classifier, used when a signer does not focus on any particular characteristic of the referent (see also section 2.2). In this view, it can be argued that verbs of motion that appear with this shape of the articulator have a classifier indeed, and that classifiers, thus, are obligatorily attached to these verbs. In other views, the finger(tip) is considered a (default) phonetic articulation, spelled out simply because the expression of the location or movement needs an articulator, or the finger(tip) handshape is considered as one of the phonological features of the verb, that undergoes a change when a classifier morpheme is added (e.g., Glück/Pfau 1998, 1999). More research is necessary for any of these views to prove correct.

Fourth, verbal classifier systems (as well as other classifier systems) in spoken languages allow variability in the choice of a classifier. Thus a noun can be categorized with more than one classifier (this is sometimes called 'reclassification'). The variability range is to some extent dependent on the size of the inventory of classifiers, and on the semantic range of the categorization. An example of this variability from Miraña (also called Bora; a Witotoan language spoken in Brazil, Peru, and Colombia) is shown below. In this instance, a more general classifier appears on the verb in (10a) and a classifier that focuses on the shape in (10b) (Seifart 2005, 80):

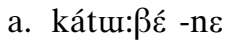
$\varepsilon:-n \varepsilon$
pihhú $\quad-k o$
fall -CL:inanimate DIST -CL:inanimate fish.NMZ -CL:pointed
'It (inanimate) fell, that (pointed) fishing rod.'
b. kátu: $\beta \varepsilon \dot{\varepsilon}-\mathrm{ko} \quad \varepsilon$ : -ko pihhú -ko
fall -CL:pointed DIST -CL:pointed fish.NMZ -CL:pointed
'It (pointed) fell, that (pointed) fishing rod.'

As discussed in section 2, classifier variation is also possible in sign languages, both for Whole Entity and Handling classifiers. This variability has been one of the reasons for proposing other, and different, terms for these elements. Slobin et al. (2003) state that the term 'classifier' is in fact a misnomer, because choosing a particular form of the manual articulator is an act of indicating some property of the referent rather than of classifying the referent. This holds true not only for classifiers in sign, but also in spoken languages. Traditionally, the main function of these elements was considered categorization. However, recent work by among others Croft (1994), Aikhenvald (2000), and Grinevald (2000) shows that categorization is not the main function, but that it is necessary for the various primary functions of each classifier category (e.g., individuation for numeral classifiers, reference tracking for verbal classifiers). In this respect, then, classifiers in sign and spoken languages are rather similar, despite the by now infelicitous term.

Example (10) also shows that the classifiers in Miraña do not only occur on the verb, but also on nouns and determiners. This is a frequent observation in spoken languages; languages with verbal classifiers often have multiple classifier systems. This is in contrast to sign languages, which only have verbal classifiers. 
A further characteristic of spoken languages with verbal classifier systems is that not all nouns are classified. Even though it is becoming clear that classification does not so much concern nouns but rather entities it can still be stated that not all entities are represented by a classifier in spoken languages. As for sign languages, it has not been mentioned in the literature that there are entities that are not classified by a particular hand configuration. This does not imply that all entities in sign languages can be represented by a classifier. Studies so far have used narrative data, often elicited by pictures, stories, and movies, that feature (restricted sets of) concrete entities. It is possible that other, particularly more abstract, entities might not take classifiers, or that they may not be represented by classifiers since they are less likely to move through space or to enter spatial relations. On the other hand, it is just as plausible that abstract entities can be assigned particular characteristics, such as shape or animacy, and enter metaphoric spatial relations. For the moment the issue remains unresolved.

Finally, we have seen that sign language classifiers do not only occur with motion and location verbs, but that they are also used in lexicogenesis (section 4), even though this issue still needs extensive research. It has been claimed (e.g., Engberg-Pedersen 1993; Schembri 2003) that this is not the case in spoken languages and that this is a point where sign and spoken language classifiers differ. However, classifiers in spoken languages can be used in word formation, too. This has not been focused on in the overview literature on classifiers, but is discussed in studies of particular spoken languages with classifier systems (e.g., Senft 2000; Seifart 2005; van der Voort 2004). The following examples from Miraña (Seifart 2005, 114) show that a noun root (úhi 'banana') can be combined with one or more classifiers. Seifart states that such combinations are compounds.

$$
\begin{aligned}
& \text { a. úhí } \\
& \text { banana (general: fruit, plant, bunch, ...) } \\
& \text { b. úhi -kó } \\
& \text { banana -CL:pointed } \\
& \text { 'banana plant' } \\
& \text { c. úhi -kó -Pámì } \\
& \text { banana -CL:pointed -CL:leaf } \\
& \text { 'leaf of a banana plant' } \\
& \text { d. úhi -Ró } \\
& \text { banana -CL:oblong } \\
& \text { 'banana (fruit)' } \\
& \text { e. úhi -Ró } \\
& \text { banana -CL:oblong -CL:chunk } \\
& \text { 'chunk of a banana' }
\end{aligned}
$$

Seifart $(2005,121)$ indicates that the meaning of the resulting compounds is not always componential and may even differ substantially from the combined meanings of the component parts. This has also been reported for signs that contain classifiers (e.g., Brennan 1990a,b; Johnston/Schembri 1999) and may be one of the grounds for the assumption that such signs are 'frozen'. Apparently, verbal classifiers in sign and spoken languages are similar in this respect. 
To summarize, recent findings in the spoken language literature on classifiers reveals that there are a number of similarities between verbal classifiers in spoken and sign languages, contrary to what has been claimed previously in the literature (e.g., Engberg-Pedersen 1993; Slobin et al. 2003; Schembri 2003). These similarities concern the main functions of classifiers: the lexical function of word/sign formation and the grammatical function of reference-tracking. Also, in both spoken and sign languages it is possible to choose a particular classifier in order to focus on a particular characteristic of an entity, although the entity may have a preferred classifier. A difference lies in the observation that sign languages only have verbal classifiers, whereas there are at least four different classifier systems in spoken languages and spoken languages may combine two or more of these systems (especially languages with a system of verbal classifiers). Comparison of some characteristics of verb classifiers in the different modalities remains unclear so far, e.g. questions such as whether there are referents that are not classified in sign languages, and whether the use of a classifier is optional, as in spoken language verbal classifier systems.

\section{Conclusion}

Various aspects of classifiers in sign languages have been discussed in this chapter, and compared with classifiers in spoken languages. Although classifiers have been the focus of much attention in sign language research (much more than verbal classifiers in spoken languages), many unresolved issues remain. Also, because of this focus, the phenomenon of classifiers may have received a larger role in sign languages than it deserves. There seem to be particular expectations with respect to classifier verbs: since the process of classifier verb formation is considered productive, many more forms and greater use of these signs are expected than actually may occur (whereas another productive process of sign formation concerning classifiers as described in section 4 is rather neglected). Like speakers, signers have several means to express spatial relations between entities and the movements of entities through space; classifier verbs are only a subset of these. Users of sign languages have a range of devices at their disposal for the expression of existence, location, motion, and locomotion, as well as the shape and orientation of entities. These devices can be combined, but signers may also use only one of these devices, focusing on or defocusing a particular aspect of an event. Finally, most work on classifiers in sign languages is based on narrative data, much of which has been elicited by pictures, comics, and movies. Use of particular stimuli ascertained the presence of classifiers in the data and it is convenient for cross-linguistic comparison, but it also biases the resulting generalizations, and consequently the results of studies that are based on the results, such as acquisition studies and comparison with similar phenomena in spoken languages.

Although many generalizations and claims have been made about classifiers and classifier constructions in sign languages, and theories have been formed on the basis of these generalizations (and vice versa), there is still much controversy in this field. It is necessary that the observations are verified by data of different genres, especially natural discourse, and obtained from large sets of users of (various) sign languages. Also, recent developments in other linguistic domains need to be taken into account. 
The results of such studies will give us a clearer view of the phenomenon, and provide a solid basis for research based on these results.

Acknowledgements: I am indebted to my colleagues Aslı Özyürek, Pamela Perniss, and Connie de Vos for providing me with data from their TID, DGS, and Kata Kolok corpora, and to them as well as to Adam Schembri and two reviewers for comments on earlier versions of this chapter. I am also grateful to my colleagues Yassine Nauta and Johan Ros for signing the NGT examples in (7). The construction of the DGS/ TID corpora was made possible through a VIDI grant from the Dutch Science Foundation NWO. The construction of the Corpus NGT was funded by an investment grant from the same foundation.

\section{Literature}

Adams, Karen

1986 Numeral Classifiers in Austroasiatic. In: Craig, Colette (ed.), Noun Classes and Categorization. Amsterdam: Benjamins, 241-262.

Aikhenvald, Alexandra Y.

2000 Classifiers: A Typology of Noun Categorization Devices. Oxford: Oxford University Press.

Allan, Keith

1977 Classifiers. In: Language 53, 285-311.

Aronoff, Mark/Meir, Irit/Padden, Carol/Sandler, Wendy

2003 Classifier Constructions and Morphology in Two Sign Languages. In: Emmorey, Karen (ed.), Perspectives on Classifiers in Sign Languages. Mahwah, NJ: Lawrence Erlbaum, $53-84$.

Benedicto, Elena/Brentari, Diane

2004 Where Did All the Arguments Go? Argument-changing Properties of Classifiers in ASL. In: Natural Language and Linguistic Theory 22, 743-810.

Bernardino, Elidea L. A.

2006 What Do Deaf Children Do When Classifiers Are Not Available? The Acquisition of Classifiers in Verbs of Motion and Verbs of Location in Brazilian Sign Language (LSB). $\mathrm{PhD}$ Dissertation, Graduate School of Arts and Sciences, Boston University.

Boyes-Braem, Penny

1981 Features of the Handshape in American Sign Language. PhD Dissertation, Berkeley, University of California.

Brennan, Mary

1990a Productive Morphology in British Sign Language. Focus on the Role of Metaphors. In: Prillwitz, Siegmund/Vollhaber, Tomas (eds.), Current Trends in European Sign Language Research. Proceedings of the $3^{\text {rd }}$ European Congress on Sign Language Research. Hamburg, July 26-29, 1989. Hamburg: Signum, 205-228.

Brennan, Mary

1990b Word Formation in British Sign Language. Stockholm: University of Stockholm.

Brentari, Diane/Goldsmith, John

1993 Secondary Licensing and the Non-dominant Hand in ASL Phonology. In: Coulter, Geoffrey R. (ed.), Current Issues in ASL Phonology. New York: Academic Press, 19-41.

Brentari, Diane

1998 A Prosodic Model of Sign Language Phonology. Cambridge, MA: MIT Press. 
Brentari, Diane/Padden, Carol

2001 Native and Foreign Vocabulary in American Sign Language. In: Brentari, Diane (ed.), Foreign Vocabulary in Sign Languages. Mahwah, NJ: Lawrence Erlbaum, 87-119.

Chang, Jung-hsing/Su, Shiou-fen/Tai, James H-Y.

2005 Classifier Predicates Reanalyzed, with Special Reference to Taiwan Sign Language. In: Language and Linguistics 6(2), 247-278.

Corazza, Serena

1990 The Morphology of Classifier Handshapes in Italian Sign Language (LIS). In: Lucas, Ceil (ed.), Sign Language Research: Theoretical Issues. Washington, DC: Gallaudet University Press, 71-82.

Croft, William

1994 Semantic Universals in Classifier Systems. In: Word 45, 145-171.

Cuxac, Christian

2000 La Langue des Signes Française: les Voies de l'Iconicité. Paris: Ophrys.

Cuxac, Christian

2003 Iconicité des Langues des Signes: Mode d'Emploi. In: Monneret, Philippe (ed.), Cahiers de Linguistique Analogique 1. A.B.E.L.L. Université de Bourgogne, 239-263.

Cuxac, Christian/Sallandre, Marie-Anne

2007 Iconicity and Arbitrariness in French Sign Language - Highly Iconic Structures, Degenerated Iconicity and Diagrammatic Iconicity. In: Pizzuto, Elena/Pietrandrea, Paola/ Simone, Raffaele (eds.), Verbal and Signed Languages. Comparing Structures, Constructs and Methodologies. Berlin: Mouton de Gruyter, 13-33.

Delancey, Scott

1999 Lexical Prefixes and the Bipartite Stem Construction in Klamath. In: International Journal of American Linguistics 65, 56-83.

DeMatteo, Asa

1977 Visual Imagery and Visual Analogues in American Sign Language. In: Friedman, Lynn A. (ed.), On the Other Hand. New Perspectives on American Sign Language. New York: Academic Press, 109-137.

Denny, J. Peter

1979 The 'Extendedness' Variable in Classifier Semantics: Universal Features and Cultural Variation. In: Mathiot, Madeleine (ed.), Ethnolinguistics: Boas, Sapir and Whorf Revisited. The Hague: Mouton Publishers, 97-119.

Denny, J. Peter/Creider, Chet A.

1986 The Semantics of Noun Classes in Proto Bantu. In: Craig, Colette (ed.), Noun Classes and Categorization. Amsterdam: Benjamins, 217-239.

Emmorey, Karen

2002 Language, Cognition, and the Brain. Insights from Sign Language Research. Mahwah, NJ: Lawrence Erlbaum.

Engberg-Pedersen, Elisabeth

1993 Space in Danish Sign Language: The Semantics and Morphosyntax of the Use of Space in a Visual Language. Hamburg: Signum.

Engberg-Pedersen, Elisabeth

1995 Point of View Expressed through Shifters. In: Emmorey, Karen/Reilly, Judy (eds.), Language, Gesture, and Space. Hillsdale, NJ: Lawrence Erlbaum, 133-154.

Fernald, Theodore B./Napoli, Donna Jo

2000 Exploitation of Morphological Possibilities in Signed Languages: Comparison of American Sign Language with English. In: Sign Language \& Linguistics 3(1), 3-58.

Fischer, Susan D.

2000 Thumbs Up Versus Giving the Finger: Indexical Classifiers in NS and ASL. Paper Presented at the $7^{\text {th }}$ International Conference on Theoretical Issues in Sign Language Research (TISLR), Amsterdam. 
Fish, Sarah/Morén, Bruce/Hoffmeister, Robert/Schick, Brenda

2003 The Acquisition of Classifier Phonology in ASL by Deaf Children: Evidence from Descriptions of Objects in Specific Spatial Arrangements. In: Beachley, Barbara et al. (eds.), Proceedings of the Annual Boston University Conference on Language Development 27(1). Somerville, MA: Cascadilla Press, 252-263.

Frishberg, Nancy/Gough, Bonnie

2000[1973] Morphology in American Sign Language. In: Sign Language \& Linguistics 3(1), $103-131$.

Glück, Susanne/Pfau, Roland

1998 On Classifying Classification as a Class of Inflection in German Sign Language. In: Cambier-Langeveld, Tina/Lipták, Aniko/Redford, Michael (eds.), Proceedings of ConSole VI. Leiden: SOLE, 59-74.

Glück, Susanne/Pfau, Roland

1999 A Distributed Morphology Account of Verbal Inflection in German Sign Language. In: Cambier-Langeveld, Tina/Lipták, Aniko/Redford, Michael/van der Torre, Eric Jan (eds.), Proceedings of ConSole VII. Leiden: SOLE, 65-80.

Grinevald, Colette

2000 A Morphosyntactic Typology of Classifiers. In: Senft, Günter (ed.), Systems of Nominal Classification. Cambridge: Cambridge University Press, 50-92.

Grote, Klaudia/Linz, Erika

2004 The Influence of Sign Language Iconicity on Semantic Conceptualization. In: Müller, Wolfgang G./Fischer, Olga (eds.), Inconity in Language and Literature 3. Amsterdam: Benjamins, 23-40.

Hendriks, Bernadette

2008 Jordanian Sign Language: Aspects of Grammar from a Cross-linguistic Perspective. PhD Dissertation, University of Amsterdam. Utrecht: LOT.

Hilzensauer, Marlene/Skant, Andrea

2001 Klassifikation in Gebärdensprachen. In: Leuninger, Helen/Wempe, Karin (eds.), Gebärdensprachlinguistik 2000 - Theorie und Anwendung. Hamburg: Signum, 91-111.

Hoiting, Nini/Slobin, Dan

2002 Transcription as a Tool for Understanding: The Berkeley Transcription System for Sign Language Research (BTS). In: Morgan, Gary/Woll, Bencie (eds.), Directions in Sign Language Acquisition. Amsterdam: Benjamins, 55-76.

Johnston, Trevor

1989 Auslan: The Sign Language of the Australian Deaf Community. PhD Dissertation, University of Sydney.

Johnston, Trevor/Schembri, Adam

1999 On Defining Lexeme in a Signed Language. In: Sign Language \& Linguistics 2(2), $115-185$.

Kantor, Rebecca

1980 The Acquisition of Classifiers in American Sign Language. In: Sign Language Studies 28, 193-208.

Kegl, Judy A./Schley, Sarah

1986 When Is a Classifier No Longer a Classifier? In: Nikiforidou, V./Clay, M. Van/Niepokuj, M./Feder, D. (eds.), Proceedings of the $12^{\text {th }}$ Annual Meeting of the Berkeley Linguistic Society. Berkeley, CA: Berkeley Linguistics Society, 425-441.

Kooij, Els van der

2002 Phonological Categories in Sign Language of the Netherlands. The Role of Phonetic Implementation and Iconicity. PhD Dissertation, Utrecht University. Utrecht: LOT.

Liddell, Scott K./Johnson, Robert E.

1987 An Analysis of Spatial-Locative Predicates in American Sign Language. Paper Presented at the $4^{\text {th }}$ International Symposium on Sign Language Research, Lappeenranta, Finland. 
Liddell, Scott K.

2003 Sources of Meaning in ASL Classifier Predicates. In: Emmorey, Karen (ed.), Perspectives on Classifiers in Sign Languages. Mahwah, NJ: Lawrence Erlbaum, 199-220.

Mandel, Mark Alan

1977 Iconic Devices in American Sign Language. In: Friedman, Lynn A. (ed.), On the Other Hand. New Perspectives on American Sign Language. New York: Academic Press, 57-107.

Martin, Amber Joy/Sera, Maria D.

2006 The Acquisition of Spatial Constructions in American Sign Language and English. In: Journal of Deaf Studies and Deaf Education 11(4), 391-402.

McDonald, Betsy Hicks

1982 Aspects of the American Sign Language Predicate System. PhD Dissertation, University of Buffalo.

Meir, Irit

2001 Verb Classifiers as Noun Incorporation in Israeli Sign Language. In: Booij, Gerard/ Marle, Jacob van (eds.), Yearbook of Morphology 1999. Dordrecht: Kluwer, 299-319.

Mithun, Marianne

1986 The Convergence of Noun Classification Systems. In: Craig, Colette (ed.), Noun Classes and Categorization. Amsterdam: Benjamins, 379-397.

Morgan, Gary/Woll, Bencie

2003 The Development of Reference Switching Encoded through Body Classifiers in British Sign Language. In: Emmorey, Karen (ed.), Perspectives on Classifiers in Sign Languages. Mahwah, NJ: Lawrence Erlbaum, 297-310.

Morgan, Gary/Herman, Rosalind/Barriere, Isabelle/Woll, Bencie

2008 The Onset and Mastery of Spatial Language in Children Acquiring British Sign Language. In: Cognitive Development 23, 1-19.

Newport, Elissa

1982 Task Specificity in Language Learning? Evidence from Speech Perception and American Sign Language. In: Wanner, Eric/Gleitman, Lila (eds.), Language Acquisition: the State of the Art. Cambridge: Cambridge University Press, 450-486.

Newport, Elissa

1988 Constraints on Learning and Their Role in Language Acquisition: Studies of the Acquisition of American Sign Language. In: Language Sciences 10, 147-172.

Nyst, Victoria

2007 A Descriptive Analysis of Adamorobe Sign Language (Ghana). PhD Dissertation, University of Amsterdam. Utrecht: LOT.

Padden, Carol A./Perlmutter, David M.

1987 American Sign Language and the Architecture of Phonological Theory. In: Natural Language and Linguistic Theory 5, 335-375.

Perniss, Pamela

2007 Space and Iconicity in German Sign Language (DGS). PhD Dissertation, University of Nijmegen. Nijmegen: MPI Series in Psycholinguistics.

Rosen, Sara Thomas

1989 Two Types of Noun Incorporation: A Lexical Analysis. In: Language 65, 294-317.

Sandler, Wendy/Lillo-Martin, Diane

2006 Sign Language and Linguistic Universals. Cambridge: Cambridge University Press.

Schembri, Adam

2001 Issues in the Analysis of Polycomponential Verbs in Australian Sign Language (Auslan). $\mathrm{PhD}$ Dissertation, University of Sydney.

Schembri, Adam

2003 Rethinking 'Classifiers' in Signed Languages. In: Emmorey, Karen (ed.), Perspectives on Classifiers in Sign Languages. Mahwah, NJ: Lawrence Erlbaum, 3-34. 
Senft, Günther

2000 What Do We Really Know About Nominal Classification Systems? In: Senft, Günther (ed.), Nominal Classification Systems. Cambridge: Cambridge University Press, 11-49.

Schick, Brenda

1990a Classifier Predicates in American Sign Language. In: International Journal of Sign Linguistics $1,15-40$.

Schick, Brenda

1990b The Effects of Morphosyntactic Structure on the Acquisition of Classifier Predicates in ASL. In: Lucas, Ceil (ed.), Sign Language Research. Theoretical Issues. Washington, DC: Gallaudet University Press, 358-374.

Seifart, Frank

2005 The Structure and Use of Shape-based Noun Classes in Miraña (North West Amazon). PhD Dissertation, University of Nijmegen. Nijmegen: MPI Series in Psycholinguistics.

Slobin, Dan I./Hoiting, Nini/Kuntze, Marlon/Lindert, Reyna/Weinberg, Amy/Pyers, Jennie/Anthony, Michelle/Biederman, Yael/Thumann, Helen

2003 A Cognitive/Functional Perspective on the Acquisition of 'Classifiers'. In: Emmorey, Karen (ed.) Perspectives on Classifiers in Sign Languages. Mahwah, NJ: Lawrence Erlbaum, 271-298.

Supalla, Ted

1980 Morphology of Verbs of Motion and Location in American Sign Language. In: Caccamise, Frank/Hicks, Don (eds.), Proceedings of the $2^{\text {nd }}$ National Symposium of Sign Language Research and Teaching, 1978. Silver Spring, MD: National Association of the Deaf, $27-45$.

Supalla, Ted

1982 Structure and Acquisition of Verbs of Motion and Location in American Sign Language.

Supalla, Ted

PhD Dissertation, University of San Diego.

1986 The Classifier System in American Sign Language. In: Craig, Colette (ed.), Noun Classes and Categorization. Amsterdam: Benjamins, 181-214.

Talmy, Leonard

1985 Lexicalization Patterns: Semantic Structure in Lexical Forms. In: Shopen, Timothy (ed.), Language Typology and Syntactic Description. Grammatical Categories and the Lexicon. Cambridge: Cambridge University Press, 57-149.

Tang, Gladys

2003 Verbs of Motion and Location in Hong Kong Sign Language: Conflation and Lexicalization. In: Emmorey, Karen (ed.), Perspectives on Classifiers in Sign Languages. Mahwah, NJ: Lawrence Erlbaum, 143-165.

Tang, Gladys/Sze, Felix Y. B./Lam, Scholastica

2007 Acquisition of Simultaneous Constructions by Deaf Children of Hong Kong Sign Language. In: Vermeerbergen, Myriam/Leeson, Lorraine/Crasborn, Onno A. (eds.), Simultaneity in Signed Languages. Form and Function. Amsterdam: Benjamins, 283-316.

Taub, Sarah F.

2001 Language from the Body: Iconicity and Metaphor in American Sign Language. Cambridge: Cambridge University Press.

Voort, Hein van der

2004 A Grammar of Kwaza. Berlin: Mouton de Gruyter.

Wallin, Lars

1996 Polysynthetic Signs in Swedish Sign Language. PhD Dissertation, University of Stockholm.

Wallin, Lars

2000 Two Kinds of Productive Signs in Swedish Sign Language: Polysynthetic Signs and Size and Shape Specifying Signs. In: Sign Language and Linguistics 3, 237-256. 
Wilbur, Ronnie B.

2008 Complex Predicates Involving Events, Time and Aspect: Is This Why Sign Languages Look so Similar? In: Quer, Josep (ed.), Signs of the Time. Selected Papers from TISLR 2004. Hamburg: Signum, 217-250.

Young, Robert/Morgan, William

1987 The Navajo Language - A Grammar and Colloquial Dictionary. Albuquerque, NM: University of New Mexico Press.

Zeshan, Ulrike

2003 'Classificatory' Constructions in Indo-Pakistani Sign Language: Grammaticalization and Lexicalization Processes. In: Emmorey, Karen (ed.), Perspectives on Classifiers in Sign Languages. Mahwah, NJ: Lawrence Erlbaum, 113-141.

Zwitserlood, Inge

1996 Who'll HANDLE the OBJECT? An Investigation of the NGT-classifier. MA Thesis, Utrecht University.

Zwitserlood, Inge

2003 Classifying Hand Configurations in Nederlandse Gebarentaal (Sign Language of the Netherlands). PhD Dissertation, Utrecht University. Utrecht: LOT.

Zwitserlood, Inge

2008 Morphology Below the Level of the Sign - Frozen Forms and Classifier Predicates. In: Quer, Josep (ed.), Signs of the Time: Selected Papers from TISLR 2004. Hamburg: Signum, 251-272.

Inge Zwitserlood, Nijmegen (The Netherlands)

\section{Tense, aspect, and modality}

1. Introduction

2. Tense

3. Aspect

4. Modality

5. Conclusions

6. Literature

\section{Abstract}

Cross-linguistically, the grammatical categories tense, aspect, and modality - when they are overtly expressed - are generally realized by free morphemes (such as adverbials and auxiliaries) or by bound inflectional markers. The discussion in this chapter will make clear that this generalization also holds true for sign languages. It will be shown that tense is generally encoded by time adverbials and only occasionally (and only in a few sign languages) by verbal inflection. In contrast, various aspect types are realized on the lexical verb, in particular, by characteristic movement modulations. Only completive/ perfective aspect is commonly realized by free morphemes across sign languages. Finally, 